Wainsztok, C.; Duran, M.; Lopez Cardona, D.; Ouviña, H.; Imen, P. "Simón Rodriguez y las pedagogías emancipadoras de nuestra América”, Ediciones del Centro Cultural de la Cooperación Floreal Gorini, Bs. As., 2013. Páginas 291-294 en Revista de la Escuela de Ciencias de la Educación, año11, número 10, enero a DICIEMBRE DE 2015. ISSN 1851-6297. ISSN EN LINEA 2362-3349.

\title{
WAINSZTOK, C.; DURAN, M.; LOPEZ CARDONA, D.; OUVIÑA, H.; IMEN, P. "SIMON RODRIGUEZ Y LAS PEDAGOGIAS EMANCIPADORAS DE NUESTRA AMERICA", EDICIONES DEL CENTRO CULTURAL DE LA COOPERACION FLOREAL GORINI, BS. AS., 2013.
}

\author{
Por María Luz Prados* \\ Universidad Nacional de Rosario, Argentina. \\ maluzprados@hotmail.com
}

Recibido: 04/07/2014 Aceptado: 18/08/2014

\section{Resumen}

En la presente reseña se comenta un libro acerca del pensamiento políticoeducativo del pensador Simón Rodriguez haciendo hincapié en su herencia y su aporte a pensar un proyecto educativo de signo emancipador para América Latina.

Palabras claves:

Simón Rodríguez - Educación - Política - Emancipación - Educación popular.

\section{Abstract}

In the present review a book about the political and educational thought of Simon Rodriguez thinker emphasizing its heritage and its contribution to educational thinking emancipatory project for Latin America sign says.

Key Word:

Simón Rodríguez - Education - Poltics - Emancipation - Popular education.

* Prof. en Ciencias de la Educación. Universidad Nacional de Rosario. Profesora Adscripta en el Núcleo Socio Educativo (Carrera Ciencias de la Educación UNR). Tallerista en grupos de Educación Popular y en el Seminario Extra Curricular "Derechos Humanos y Educación: genealogía de una conquista social". 
Revista de la Escuela de Ciencias de la Educación, año 11, número 10, enero a diciembre de 2015. Páginas 291-294. ISSN 1851-6297. ISSN en linea 2362-3349. Wainsztok, C.; Duran, M.; Lopez Cardona, D.; Ouviña, H.; Imen, P. "Simón Rodriguez y las pedagogías emancipadoras de nUestra América", Ediciones del Centro Cultural de la Cooperación Floreal GorinI, Bs. As., 2013. María Luz Prados

Este libro objeto de la reseña surge de la reflexión colectiva de los/as autores cuya meta es recuperar el pensamiento de Simón Rodríguez. Esta búsqueda tiene como horizonte, no solo conocer el pensamiento de Rodríguez sino, principalmente, constituirse en un aporte a la construcción de un proyecto político-pedagógico de signo emancipador para América Latina hoy.

Recuperar el legado político-educativo de este pensador tiene como fin analizar aquellos elementos que nos permiten pensar un modelo educativo transformador para la Patria grande, pero no con fines museísticos sino para aprehender su herencia viva.

Los/as autores/as inician este recorrido preguntándose acerca de la relación entre lo educativo y lo político reconociendo la insuficiencia de lo educativo como campo autónomo que puede propiciar practicas emancipatorias. Entienden a lo educativo como subsumido a dimensiones filosóficas, políticas y culturales y, por lo tanto, afirman que las transformaciones sociales, políticas, económicas, culturales y las educativas deben ir de la mano en pos de una trasformación social. Luego se preguntan por qué Simón Rodríguez entre tanto pensadores/as latinoamericanos/as y se responden, porque fue el pedagogo de la primera emancipación latinoamericana y porque fue el primero en proponer un modelo educativo para las nacientes repúblicas.

Bajo el lema "Inventamos o erramos" Rodríguez condensó la búsqueda por formas políticas, sociales, culturales y educativas que impliquen una ruptura con las practicas coloniales que subyugaban a los pueblos de América. Su horizonte era construir una educación democrática y popular que formase ciudadanos/as para las repúblicas en formación. Simón Bolívar llamo a su maestro para que ponga en práctica sus ideas en la Escuela de Chuquisaca en Bolivia. Como muchas experiencias transformadoras tuvo una corta duración debido a los recelos que cosechó entre las clases acomodadas de esa ciudad pero alcanzo para poner en entredicho los fundamentos de la revolución. El pensamiento de Rodriguez se puede expresar en tres elementos: escuela popular para todos/ as (negros/as, indios/as, mestizos/as, criollos/as de todas las clases sociales), formación del ciudadano/a para que realmente ejerza sus derechos y se sacuda la herencia servil del colonialismo, y nuevas metodologías de enseñanza que se opongan a los métodos de la colonia.

Lo interesante de la mirada de los autores es la permanente relación entre el pasado y el presente, entre la acción y la reflexión. A lo largo de los capítulos se puede apreciar este juego en el cual se conjuga, a la vez, la reflexión individual y la colectiva. En la introducción se aclara que el libro surge como producto de todo un proceso de reflexión e investigación que encaró el grupo de trabajo que conforman los/as autores/as en el cual investigan las pedagogías emancipadoras de Latinoamérica.

En el primer capítulo los/as autores sitúan a Simón Rodríguez en su tiempo histórico y reflexionan acerca de la educación de ese momento, a la vez exami- 
Revista de la Escuela de Ciencias de la Educación, año 11, número 10, enero a diciembre de 2015. Páginas 291-294. ISSN 1851-6297. ISSN en línea 2362-3349. Wainsztok, C.; Duran, M.; Lopez Cardona, D.; Ouviña, H.; Imen, P. "Simón Rodriguez y las pedagogias emancipadoras de nuestra América", Ediciones del Centro Cultural de la Cooperación Floreal Gorini, Bs. As., 2013. María Luz Prados

nan como su pensamiento se inserta en un clima de época a la vez que marca serias rupturas. En el capítulo 2, Carla Wainsztok hace un parangón entre la propuesta político-pedagógica del pensador y las pedagogías actuales encontrando rupturas, continuidades y desafíos. Mientras que Maximiliano Durán en el capítulo 3, desglosa el pensamiento de Rodríguez analizando distintos conceptos como igualdad, democracia, ciudadanía, a la vez que polemiza con análisis realizados por otros autores. En el capítulo 4, Diana María López Cardona se introduce específicamente en la concepción de conocimiento sustentado por Rodríguez y las finalidades que enunciaba que debía perseguir la educación. Por otro lado, Hernán Ouviña en el quinto capítulo debate acerca de la idea de las herencias y los legados y de cómo retomar el legado del Rodríguez pero traicionándolo para serle justos. A la vez, afirma que la educación popular es el motor de la emancipación latinoamericana por lo que abre varios interrogantes para pensar en la actualidad. Finalmente en el último capítulo Pablo Imen retoma las ideas de Simón Rodríguez para pensar la Ley Orgánica de Educación de Venezuela y en qué medida ésta es heredera de su pensamiento.

A nuestro parecer esta búsqueda emprendida por los/as autores/as tiene gran relevancia y actualidad ya que pone en debate la relación entre lo político y lo educativo, entre lo social y lo político, no desligando el modelo educativo esbozado por el pensador de su práctica política. Por otro lado, porque marca una agenda de discusión para quienes militamos por una transformación social ya que nos indica la necesidad de retomar nuestra herencia latinoamericana para reflexionar acerca del modelo de educación que tenemos y cómo andar el camino hacia su transformación. 
